\title{
Study on improving the teaching quality of English curriculum of self-taught major
}

\author{
Wanjuan Ding \\ College of materials science and engineering, Nanjing Forestry University, Nanjing, 210037, China \\ hunter2011@foxmail.com
}

Keywords: Self-taught Major, English Curriculum, Teaching Quality

\begin{abstract}
Through the form of questionnaire survey and individual interviews, carry on sample investigation of English learning situation of the students who major in Wood Science and Engineering in School of Materials Science and Engineering, analyze and summarize from the learning motivation, learning interest, learning strategy, teaching effect and so on, start from the actual situation in our school, propose measures and methods to improve teaching quality of self-taught professional English.
\end{abstract}

\section{Introduction}

Self-taught examination was a form of higher education, which was a combination of social study, personal self-study and national examination. As an important part of the self-study examination system of higher education,social study was an important link between individual study and national examination. My institute has undertaken self-taught major of wood science and engineering for more than 10 years. With a good social reputation, rich teaching resources, strict quality management and strong campus atmosphere, it has attracted the students who failed in the college entrance examination, vocational school and technical secondary school students all over the country, cultivated a string of qualified graduates for the society. ${ }^{1}$

Teaching quality was the core issue of the school, how to improve the teaching quality of the teaching quality of the self-study exam was always the core issue of our college students. As a major courses, college English of self-study examination (two volumes) has been a required course in training plan of wood science and engineering self-taught professional in our academy. It makes self-taught students grasp the basic knowledge and English language skills, and lay a solid foundation for cultivating preliminary ability of listening, speaking, reading and writing of students. How to carry out effective English classroom teaching according to the present situation of the existing characteristics of self-study examination of English curriculum and student learning, was the key to improve the teaching quality of self-taught English .

\section{The learning situation of professional English of self-taught major in our college}

In order to better reflect the English learning status of our college students, this study randomly selected 95 undergraduate students who major in self-taught professional in materials science and engineering as the research object, in which there were 54 boys and 41 girls. The distribution of the grade respectively were: Grade one accounted for $3.2 \%$; Grade two accounted for $38.9 \%$; Grade three accounted for $4.2 \%$; Grade four accounted for $53.7 \%$. 


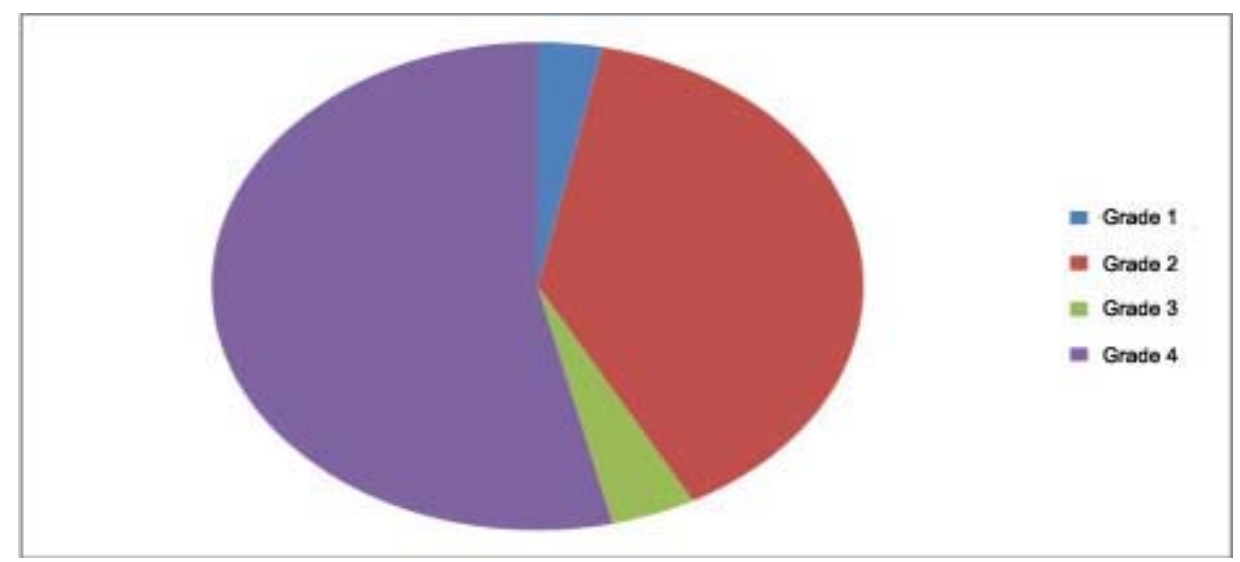

Figure.1. The grade distribution of the surveyed students

In addition,to take the method of combination of questionnaire and individual interview. The investigation content mainly involved the evaluation of the self-taught students for the self-taught English teaching, English learning strategy, learning interest, learning motivation and the passing rate of academic examination. The questionnaire survey mainly used the classroom time, and a total of 100 questionnaires were issued, and 100 copies were recovered. The recovery rate was $100 \%, 95$ valid questionnaires, the effective rate was $95 \%$. The results of the questionnaire survey showed that:

Our college students' English learning motivation was clear, but the interest in learning English was weak, and self-confidence was not strong. According to the results of the survey, most self-taught professional students had a full understanding of the importance of learning English, and quite objective and rational, but there were still a few students not clear about their learning motivation and purpose, and they just had strong utilitarian.

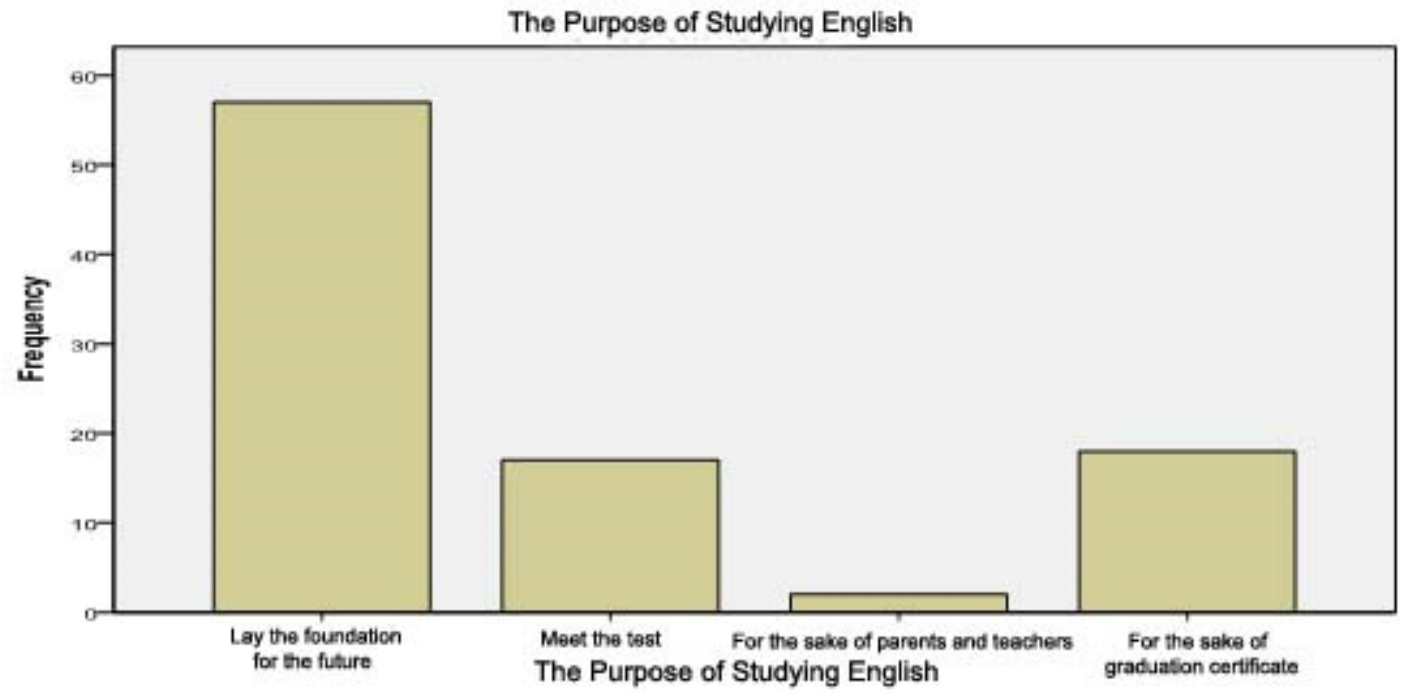

Figure. 2. Study destinations statistic of self-taught major students

In term of learning interest, the students who were very interested in learning English were only $21.1 \%$, the number who did not like was the most.In addition, the students felt low confidence about learning English well. Through the cross analysis of learning interest and learning confidence, we found that the confidence of the students who had a strong interest in learning were also greatly increased, and vice versa. Therefore, to solve the problem of students' learning attitude and improve their confidence in learning English, we should arouse students' interest in English learning, and thus lead to the improvement of learning confidence. 
Table 1. The interest in learning English * the confidence of learning English

\begin{tabular}{|c|c|c|c|c|c|}
\hline \multicolumn{6}{|c|}{ Count } \\
\hline & & \multicolumn{3}{|c|}{ the confidence of learning English } & \multirow[b]{2}{*}{ Total } \\
\hline & & Quite confident & Common & Self-distrust & \\
\hline \multirow{3}{*}{$\begin{array}{l}\text { the interest in learning } \\
\text { English }\end{array}$} & Like & 14 & 4 & 2 & 20 \\
\hline & Common & 4 & 38 & 7 & 49 \\
\hline & Dislike & 1 & 4 & 21 & 26 \\
\hline \multicolumn{2}{|l|}{ Total } & 19 & 46 & 30 & 95 \\
\hline
\end{tabular}

The students in our college have a general lack of effective English learning strategies. The so-called learning strategy, was to establish a complex program related to the learning process with specific purposes,in order to improve the learning effectiveness and efficiency of learners. ${ }^{2}$ The English learning initiative and effectiveness of the self-taught students were poor, at the same time,the planning was lacked,and the learning efficiency was low in the learning process. The questionnaire survey showed that only $13.6 \%$ of the students could often sum up the learning method, while the $24.5 \%$ students had never concluded their English learning methods and experience. In addition, the learning volition of self-taught students was weak in the process of learning English, and lack of sustained the courage and perseverance to overcome difficulties, only $27.1 \%$ would head-on when facing difficulties. It was found from the cross analysis results of the study method and learning volition that the ability of the students who often summed up the study method to overcome the difficulties would be increased in doing homework.

Table 2. Overcoming a difficult situation * summing up the study method

\begin{tabular}{|c|c|c|c|c|c|c|}
\hline \multicolumn{7}{|c|}{ Count } \\
\hline & & \multicolumn{4}{|c|}{ summing up the study method } & \multirow[b]{2}{*}{ Total } \\
\hline & & At regular intervals & Often & Once in a while & Never & \\
\hline \multirow{3}{*}{$\begin{array}{c}\text { Overcoming a } \\
\text { difficult } \\
\text { situation }\end{array}$} & $\begin{array}{l}\text { Facing difficulties on my } \\
\text { difficulties }\end{array}$ & 10 & 5 & 10 & 2 & 27 \\
\hline & $\begin{array}{l}\text { First, full of vigor,but slowly } \\
\text { slacked off. }\end{array}$ & 3 & 7 & 31 & 14 & 55 \\
\hline & It did not matter. & 0 & 1 & 4 & 6 & 11 \\
\hline \multicolumn{2}{|r|}{ Total } & 13 & 3 & 45 & 22 & 93 \\
\hline
\end{tabular}

The teaching efficiency was low, and the teaching method was single. In the process of learning foreign language, the input of discourse information was very important. The quantity and quality of the received discourse of the learners could influence the learners' language output, communication and the whole language learning process. Teacher talk was the most important source of information input in classroom foreign language learning. It can be used to determine the effect of teaching. ${ }^{3}$ While the survey showed that the foundation of the self-taught students was poor,and the teachers did not timely adjust the language input in class, so students' quality of attending a lecture was very low, $26.3 \%$ of the students in the classroom fully did not understand the language output by the teachers. The difficulty levels order in the process of students studying English were: listening, grammar, speaking, writing and reading. At the same time, the students reflected that the teaching method was single, mainly in teaching, lack of a variety of teaching mode.

The overall pass rate of English (two) was low, among them, vocabulary and reading comprehension is the most difficult. The pass rate of English (two) of the students participated in the survey was $56.8 \%$. One-shot students accounted for $53.7 \%$. The students who were the second time to pass accounted for $28.4 \%$.More than three times was $10.7 \%$. In the exam questions, students who generally thought that the reading comprehension was the most difficult was $33.9 \%$, followed by the grammatical questions which accounted for $23.2 \%$, and word spelling was $20.5 \%$. 


\section{Reason Analysis}

The students had a weak foundation, and low interest in foreign language learning.Most students major in self-taught in our college came from secondary school students or the students failed in college entrance exam. There were some on-the-job people going back to school to learn. The English level of the students was uneven, and the whole was weak. A few students could tighten with the teachers' lecture rhythm in the classroom, the majority of students did not review and preview in time under the weak condition, resulting in certain obstacles in interaction between teachers and students in class. The acceptance of new knowledge was slow, and learning efficiency in class was poor. In such a vicious circle, students had the fear and inimical emotion of learning a foreign language, so the attendance rates were low.

Teaching management of the college needed to be strengthened. The management of Self-taught major involved student status management, examination management, dormitory management, teaching quality management, teaching management, productive practice and other practical aspects, although the human resource management of college self-taught professional was extremely limited, and strength weak. The management personnel must spend much time on miscellaneous work. In the course of English teaching, in addition that the attendance of the English class was low, the teachers team construction should be strengthened.

The English teacher did not take it seriously. Self-taught major had its natural advantages to be set in colleges and universities, most serving teachers were foreign language teachers of colleges and universities with high quality and strong ability, but they did not take self-taught teaching seriously.It showed in the lack of teaching materials, and less understanding of the students. The teaching target was not accurate,and the teaching method was single, and there was a certain problem in the classroom organization, classroom management and communication with students.

\section{Measures and Suggestions}

Teachers changed the teaching ideas, and innovated teaching mode and teaching method. In view of the special characteristics of the students, how to organize the classroom teaching and improve the students' English level were the important problems for every English teacher. The goal of College English teaching was to "make the learners master the basic knowledge and language skills in English, so that it can have good reading ability, and a certain ability of English-Chinese translation and listening, speaking, reading, writing and Chinese-English translation." The teaching material of English self-study tutorial were divided into two volumes, Volume one 25 units, volume one 15 units. According to the characteristics of the teaching material,how the teacher to arrange the class distribution,organize teaching material, design classroom teaching, How to use teaching strategy to improve the teaching quality was the problem that every English teacher needed to study and explore. ${ }^{4}$

First of all, teachers should have a positive attitude, and establish a scientific concept of English teaching. Teaching is a kind of art, a good atmosphere in the classroom need good interaction between teachers and students, teachers should teaching students according to their aptitude, according to the students' foundation and characteristics, to organize effective classroom teaching, make teaching objectives and excavate the content of the teaching material, continuous change and innovation, strengthen communication and exchanges with the students.

Secondly, innovated the teaching mode, followed the trend of the times. The current popular network teaching resources could be made full use to carry out $\mathrm{Mu}$ class and micro teaching. The students could make the teaching knowledge point record he or did not understand into a small screen, and use flip classroom to improve and strengthen the students' learning difficulties in the way of the combination of offline and online. At the same time,scenario teaching,dialogue instruction, anchored instruction and teaching model the students liked could be used to stimulate students' interest in learning English, and improve students' self-confidence and achievement.

Third, according to the different English teaching link,to take different teaching method. In reading comprehension, starting from the characteristics of the examinee, closely combined with the 
requirements of teaching outline. Jingjiang scouring or explain in brief for more practice. Try to make students the knowledge mastery, flexible use. In vocabulary teaching, aiming at the characteristics of self-study students rote ubiquitous and context to guess the meaning of the correct rate is not high, have a definite object in view to self-taught students vocabulary learning strategies were guidance and training, let them use similar words or associations to expand the amount of words, or using image, imagine to deepen the understanding of vocabulary.

Carried out all kinds of social organizations and activities related to English, stress the role of the hidden curriculum. Hidden curriculum was a curriculum that was presented in a implicit and indirect way. It was the experience of all the school education acquired by students in the dominant curriculum, and the hidden curriculum included the conceptual hidden curriculum, the material hidden curriculum, the institutional hidden curriculum and the psychogenic hidden course. ${ }^{4}$ As a college-running self-taught major, there was a huge advantage in the hidden curriculum. All the material hidden curriculum of self-taught students in school including the school buildings, the campus environment, the library are the same with the undergraduates, but by contrast, the conceptual hidden curriculum construction was strengthened. English class was just a small part of English learning, how to expand the students' English ability in the classroom was imminent.

First of all, carried out regular activities, like English Clubs, English Salons, etc.. So far, the students major in self-taught had rarely participated in the English club and various English activities. In fact, the environment of higher education institutions was extremely favorable external environment compared with other vocational colleges,students could actively invite the planning undergraduates or the students major in English to the club, invite the foreign guest to guest-star, carry out English salon, English teachers and managers need to organize relevant activities actively, cultivate students' interests in English, train students listening and speaking ability, enhance confidence in their English learning. At the same time, through the communication and exchange of English salon, teachers and students, students and students could better know each other, and find what the problem of English learning was.

Second, carried on regular English film appreciation activities. In the survey, the beat way for students to learn English is to watch the film and television drama. Now the network was more developed. There were all kinds of good English movies and TV series. Chose the film that students were interested in, to learn the more popular spoken English or sentence patterns, and strengthen the students' ability to speak. At the same time, culture penetration can be added into. Some classic movies not only had pure English, but also reflected the history and culture of the Anglo American countries. Only the national culture was known, can we learn their language better, and communicate better with foreign friends, enjoy the fun of learning English and expand their horizons, making them out of the sentence word learning the text by heart, to show a more rich English world which is closely linked with the real world for them.

Study the exam subjects, improve the classroom teaching quality. From the self-taught English questions, we could see that the exam of this course mainly inspected the basic language knowledge and skills of the students, focused on the ability of words' listening speaking reading and writing, and the the application of simple grammar,the ability of English reading and primary translation,as well as the effects of some cultural background knowledge in students. For the candidates who was the first time to participate in self-study examination, there was a certain degree of difficulty.

Before the exam, the teachers should carry on part five in advance, then,summed up and explained the problems of the students in the paper in a timely manner, for different types of questions skills summarized. At the same time, brought the analysis results of examination paper into usually classroom teaching, focused on explaining vocabulary, sentence patterns and grammar that appeared more frequency in the test, so to do more targeted and clear priorities. Teachers should pay more attention to the backwash effect of the test on the teaching, better use instrumental motivation to improve the efficiency of teaching and learning,so that students' English learning in different stages have different goals and motivation, so as to avoid to cease to learn and the fossilization phenomenon. 


\section{Acknowledgments}

This paper was the priority subject of higher education curriculum reform in Jiangsu province in 2013, and the topic name is Research on restructuring curricula system of forestry specialties under the background of building beautiful China. NO.: 2013JSJG039.

\section{References}

[1] J. Zhou, X.C. Zhu.Reflections on improving the quality of the effective way of self-study. Journal of Nanjing Institute of Technology (social science edition),2006(12)

[2] Z.G. Hu edited.Educational psychology. Education Science Press, 2011

[3] C. Peng.A survey of English teachers' language adjustment and different levels of learners' needs. Journal of Southwest Agricultural University (social science edition),2012(10)

[4] P.Y. Lv.The combination of constructivism and implicit curriculum in Higher vocational English teaching reform. Jingdezhen Comprehensive College Journal, 2010(6) 